\title{
Teaching Mathematics in Tertiary Education Through Collaborative Work
}

\author{
J. Justino \\ Research Centre for Mathematics and Applications (CIMA) \\ Polytechnic Institute of Setúbal \\ Setúbal, Portugal \\ julia.justino@estsetubal.ips.pt
}

\author{
S. Rafael \\ Setúbal School of Technology \\ Polytechnic Institute of Setúbal \\ Setúbal, Portugal \\ silviano.rafael@estsetubal.ips.pt
}

\begin{abstract}
This paper arises from a study conducted on a new mathematics' course unit of a tertiary technological course taught in a polytechnic institute where a learner-centred approach was applied. The design of the constructive pedagogical alignment of the course unit integrated the objectives, contents, assessments and the information obtained in the surveys carried out on students, as well as the training techniques chosen. The collaborative working group was the main active learning process chosen in this application of the learner-centred approach. Challenges, difficulties and benefits from applying this active learning process are considered in this paper. Some outcomes of the academic performance are also presented and discussed.
\end{abstract}

Keywords-learner-centred approach; collaborative work.

\section{INTRODUCTION}

In Portuguese tertiary technological education, teachers are not required to have a formal pedagogical training in order to enter into the career structure, since having technical and scientific skills on the teaching area is considered enough. Thus, teachers only have as training reference the traditional teacher-centred methods $[1,2]$. This kind of training, in which the teacher is the agent that defines and disseminates the subjects and its knowledge, remains theoretical in focus, doesn't foster the development of key competences needed by students for the modern economy and reduces the applications of the subjects on problems of the real world [1]. Furthermore, first year students' integration into tertiary education courses is hampered by their adaptation to the operations of a higher education institution, a new teaching-learning process and a new society [3]. In the special case of tertiary technological courses and engineering degrees, the lack of mathematical background by students is a major contribution to the worsening of this adaptation and the consequent early school drop-outs $[4,5]$. In order to overcome these problems, the application of a learner-centred approach in mathematics, in which the student takes responsibility for its own learning process and the teacher assumes the role of facilitator of that process, is presented in this paper as a valuable tool [6].

\section{RESEARCH METHODOLOGY}

Two research methods were applied in the study: a quantitative method and a qualitative method [7,8]. These methods were sequentially or simultaneously applied according to issues raised and data to be evaluated.

In the quantitative method, based on students' investigations and assessments, three different surveys were carried out during the term time: initial, intermediate and final. The initial survey, with multiple-choice questions, aimed to identify students' profile; the intermediate survey, with openended questions, enabled to review the students' learning process development during the implementation of active learning techniques; the final survey, with multiple-choice questions, allowed to check whether the initial objectives were achieved. All surveys were anonymous in order to protect the students' identity and privacy, encouraging them to answer with realism and truth.

The qualitative method, based on the interpretative approach given by the teacher's personal observation in classes upon the students' behavioural attitude along the learning process, provided useful information about how the learning process was being conducted.

\section{CONTEXT OF APPLICATION}

In 2014 a new type of short-cycle tertiary educational programme (2 years - 180 ECTS) was added to the range of course offerings in polytechnics of Portugal, called Curso Técnico Superior Profissional (CTeSP). This programme has a significant practical and technological component and stronger links to the labour market needs, suitable for students from vocational education to whom hitherto tertiary education was not attractive. Since the large majority of students attending a CTeSP doesn't have the same educational background as the general secondary students [4,5], the pedagogical strategy adopted in a CTeSP should boost the typical features of practical and working life training. The study presented in this paper is considered representative within the CTeSP given at the Setúbal School of Technology.

The pedagogical strategy adopted in the CTeSP presented in this paper was the Project Based Learning (PBL), aggregating most of the technical course units within the course schedule. However, the mathematics' course unit, although its importance regarding the students' training was recognised, was not included on the learning activities by projects due to the strong technological nature which characterises this CTeSP. So, it became necessary to define 
which pedagogical project should be adopted in the mathematics' course unit.

Since a CTeSP is a short-cycle programme, the following challenges arose, considering some of the students' skills development.

Speed up the students' adaptation to the tertiary education system.

Speed up the students' adaptation to the pedagogical methodology to be applied.

Foster greater ability, commitment and autonomy over the curricular unit contents.

Increase the work capacity and improve the students' self-evaluation.

Develop the key competences of students.

Integrate the key competences and course objectives into the course unit.

By pedagogical strategy to be applied in the course unit, the following challenges were raised.

The choice of the teaching method and its related techniques to be applied, considering the diversity of learning styles and learning habits that students from vocational education carry over into the classroom.

The standardization and articulation of the joint interdisciplinary strategies.

By academic performance, the following challenges were also raised.

The motivational strategies to be provided in order to improve the success rate in mathematics.

The reduction of the early school drop-outs.

These challenges, among many others, have provided an impetus for the study of which pedagogical methodology should be applied, for in practice several teaching methods, mixed or not, applied to a course or to its curricular units may coexist.

\section{TEACHING Method}

Within the various teaching methods, the learner-centred approach was the chosen one. This method allowed to answer to the previous challenges, converting them into curricular objectives without putting aside the cross-cutting and interdisciplinary issues as the standardization with the other curricular units or the students' autonomy [9]. The flexible profile of this method also allowed to correct learning pathways during term time, change the format of contents, adapt techniques and improve the learning activities. In fact, the implementation of the learner-centred approach seeks the enforcement of several tasks (conceiving, designing, implementing, reviewing and adapting). Those tasks require a link between the contents, the objectives, the students' training needs and the training techniques to be applied $[2,10]$.

The active learning techniques applied in the classroom environment of the mathematics' course unit depended on the qualitative and quantitative assessment, the students' behavioural attitude (individually and in team) and the specific objectives for each class within the mathematical contents and the need to optimize the students' working time, always providing them the necessary learning activities. In this context, the collaborative working group was considered a suitable active learning technique, being the most applied throughout the term time.

\section{COLlaborative Working Group}

In a collaborative working group its members support each other around common targets that are negotiated between them. The established interpersonal relations do not take into account any kind of hierarchy and so the leadership is shared or allowed, existing mutual trust. Language is the mediation facility and the key for the good understanding between the group members. So, the communication skills are developed and the co-responsibility in actions shared by all members is emerged. Autonomy, visualisation and conceptualisation are achieved through the development of learning activities within a collaborative group, highlighting that this environment enables the construction of knowledge that affects various aspects of the personal skills. In fact, the collaborative working group offers learning, study of subjects, discussion, basis and defence of ideas, constructive criticism, negotiation or mediation of positions, motivation, cooperation, spirit of openness to understand others, self-evaluation and evaluation of others, time management, among other personal skills [11].

So, within collaborative working group, students are requested to develop academic skills as well as key competences. These students possess a more positive attitude, greater self-esteem and social integration and more ability to withstand changes, adjustments and tensions that come with academia [12, 13]. However, despite its many benefits, a collaborative working group may not work properly due to diverse intrinsic and extrinsic factors. A strong personal incompatibility, socialisation difficulties or excessive leadership are factors that can be detected from the teacher's point of view. There are other factors not so easy to track that damage the success of a working group, such as the selectivepassive resistance of one of its members or the existence of different working and learning patterns.

\section{IMPLEMENTATION OF THE COLLABORATIVE WORKING GROUP}

The course coordinator divided students by four teams of four members each, which remained the same in all course units.

In the mathematics' course unit the learning activities of the collaborative work were planned under the objectives and contents as well as the organizational aspects of each class. So in each class, after a short exposure of its topic followed by an oriented debate, each team had the same set of questions to be solved individually by only one of its members. Then students of different teams that had solved the same question joined to discuss that question and returned to the starting team to share the question's resolution with its peers. In this context other adapted variations of learning techniques were also applied 
such as Jigsaw [14] and Gallery Walk [15], due to the need of fitting these techniques into a specific topic or a specific learning objective over a given period of time. Furthermore, the use of this adapted variations of learning techniques generated a new dynamic in classes which enhanced the students' motivation.

In the first class of mathematics' course unit an initial survey was carried out aimed to identify the students' study habits and the students' attitude in classroom.

On how the students study, the initial survey shown that $72 \%$ of the students studied individually, $17 \%$ studied with a colleague e only $11 \%$ studied in group. On students' study habits and preparation for evaluations, $56 \%$ of the students stated to often summarise the contents to study later, or next to the evaluation, $33 \%$ stated to only prepare themselves in the run-up to the evaluation, since they had a long memory, and only $11 \%$ of the students stated to prepare themselves on a daily basis by frequent reviews. From the responses received, it can be noted that students memorized the contents by summarizing them, not showing evidence of any other study mechanism to assimilate knowledge. Furthermore, by observation in classes it became clear that students didn't had long-term study habits, either individually or collectively.

On students' attitude, only $11 \%$ of the students stated to actively participate in classrooms. The remaining $83 \%$ stated to be passive. This passive attitude, from previous school years, is typical on a strong teacher-centred education in which the participation of students in not encouraged. So the need for an active and participative attitude enhanced the need for applying collaborative group techniques as a mean of supporting effective learning.

In the mid-term an intermediate survey was conducted for assessing the implementation of the learning process applied. It was found that $81 \%$ of the students welcomed the collaborative working group. The most relevant aspects were the sharing of expertise, the mutual assistance in solving problems and the group dynamics. The most negative aspect, stated by $30 \%$ of the students, was the difficulty in having a four hours activity within which $19 \%$ also stated that they would have liked more time for the activity. This result is not significant and may be associated with the lack of study habits and focus on activity.

All this information contributed to adapt the type and form of the learning activities in order to work out students towards a more participative and collaborative work and a shared study.

In this sense, the method of evaluation implemented in the mathematics' course unit was defined following the constructive alignment and curricular consistency which integrates the topics to be studied and the learning outcomes to be achieved, considering the depth of contents based on
Bloom's taxonomy. The students' assessment consisted in three training tests, one oral test, two summative tests and peer review, with students being encouraged to achieve $80 \%$ of the contents' skills on training tests. These assessment elements were distributed in a balanced way between all classes, keeping the students committed to learning throughout the term time. In fact, on the intermediate survey students pointed the method of evaluation as one of the major strengths of the learning process.

\section{OUTCOMES OF THE IMPLEMENTATION}

On the final survey, $75 \%$ of the students stated to have been encouraged to participate and to discuss the topics over classes which contributed to a more participative attitude along the learning activities, providing a good development in their performance. The remaining $25 \%$ stated not to always have an active and participative attitude during the learning activities.

On collaborative work, $69 \%$ of the students stated to feel supported by the remaining team, facilitating their social integration through sharing of knowledge relating to the curricular unit, $25 \%$ stated that the support of the remaining team was not frequent and only $6 \%$ of the students showed social and interaction difficulties with the remaining team.

On the working group dynamics during the learning activities, $88 \%$ of the students considered to always have worked well, $6 \%$ considered that the team have often worked well and only $6 \%$ of the students considered that the team didn't work out so well.

On the group learning, $81 \%$ of the students stated to have learned more in team than individually, achieving the goal of information and knowledge sharing, and 19\% would have preferred to work alone.

Overall, $87 \%$ of the students stated to have developed relationship skills with all classmates and 13\% stated that only for some of the team colleagues. This indicator is quite important since it emphasizes the application of collaborative working groups at the beginning of study programmes (first year) in order to improve relationships, balance the acquired knowledge, provide the sharing of knowledge, work as key to the motivation and mutual assistance and foster the adaptation to the teaching method.

\section{OUTCOMES OF THE ACADEMIC PERFORMANCE}

Through teaching and learning activities the performance of teams and students was evaluated by the above-mentioned means, linking the way of working to the collective and personal characteristics within each team. 


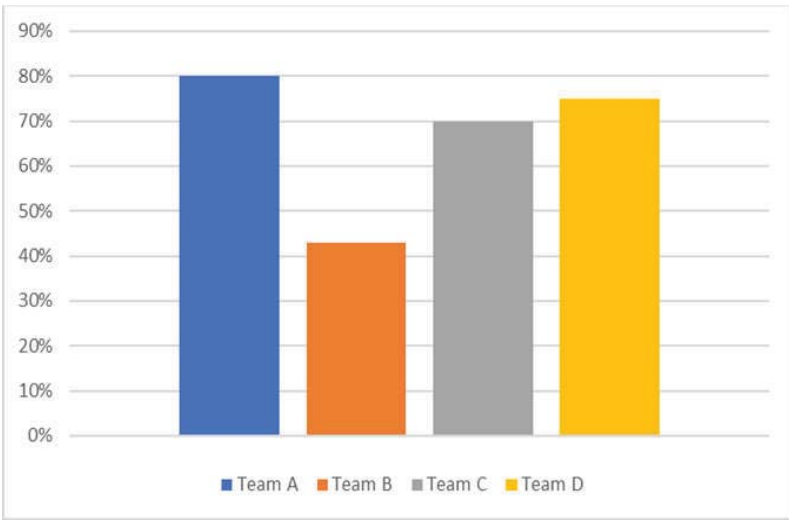

Fig. 1. Outcomes by team

In Fig. 1 the ranking of the teams' performance is presented in a bar graph (with teams A, B, C and D). Each team member was evaluated by the working dynamics, the good relationship and the acquisition of the desired skills.

The most relevant aspects of each team are summarised below.

Team A - characterised by shared leadership, adequate cohesion and uniformity in interpersonal relations and knowledge, fast learning capacity and wider application of skills shared by all members. This team had the best pupil of the class, that provided a high dynamic in knowledge sharing, and records the best global outcome.

Team B - characterised by lack of leadership, weak cohesion and interpersonal relations, diversified knowledge and communication difficulties. Despite efforts to motivate and encourage, this team failed to achieve the necessary skills to be successful.

Team C - characterised by strong leadership with passiveness of the remaining members, moderate cohesion, diversified knowledge and some communication difficulties between its members. However, this team was able to work out some skills and records a positive outcome.

Team D - characterised by shared leadership, strong commitment, great sharing capacity and excellent cohesion. Although there was a huge lack of background knowledge among its members, this team developed the desired skills and records the second best outcome.

It was important to notice that the collaborative working group provided the training for knowledge sharing and the development of metacognition, clearly checked in teams D and A. The collaborative working group was the motivation and commitment booster in problem-solving within all teams and the communication key between team members at different stages of the problem-solving process and at different stages of the learning process. In addition, it was also noted the respect for the individual pace of work of each student within the team dynamics.

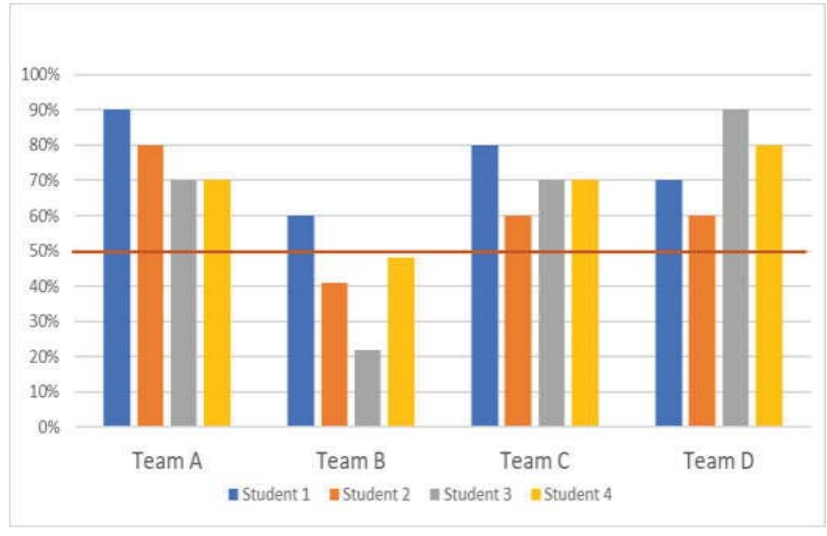

Fig. 2. Students' outcomes

In Fig. 2 the performance outcomes of each student is presented by team. Overall, a good students' performance is to be noted in teams $\mathrm{A}, \mathrm{C}$ and $\mathrm{D}$, where the collaborative work was essential for its success (with rankings above 50\%). In team B, there is to report the poor performance of two members (student 2 and student 3 ) by mismatch and passive resistance which caused their divestment on the course unit' skills. There is also to report the under-performance of student 4 to the detriment of other course units at final stage of the term time. This situation led to team B decommissioning, withstanding only the member with higher potential (student 1).

Furthermore, it should be noted that external activities, as the final term project evaluation and evaluations by other course units that didn't use an active learning methodology, as well as a false sense of security caused by the good results produced during term time, damaged the performance of team B. Even so, in the final survey, $60 \%$ of the students classified the learning process applied to mathematics' course unit as good or excellent and the remaining $40 \%$ as satisfactory.

\section{CONCLUSIONS}

Mathematics is a cross-cutting scientific area whose contents, although necessary for students' training, hardly fit into projects of strong technological nature. So, the application of active learning techniques established links with the other technical course units of a CTeSP taught in PBL. This contributes for the development of the students' key competences, such as team work, autonomy, criticism, communication, positivism, ethics, organization and time management.

The learner-centred approach enabled more flexibility in adapting the learning techniques to the new challenges that arose during classes, incurring an ongoing reflection based on the partial performance outcomes and on the qualitative data obtained throughout the learning activities. This flexibility proved to be an instrument for continuous improvement during term time, unlike teacher-centred approach that, in general, is more rigid only allowing corrections for the next academic year. 
In terms of teaching work, even though it is a rewarding experience, it is very demanding and challenging due to its multivariable dimension. In fact, from the necessary dynamics needed to be established in the classroom to the pooling of contents and training techniques with the task of being the facilitating role in the students' learning process, everything as to be properly considered and measured.

The collaborative working group is a positive contribution to the students' interaction by building skills in problemsolving. It develops motivation towards the opportunity to test their ideas against other team members. Also, this linking of concepts facilitates the students' adaptation to academia, reduces the drop-outs rate and increases the success rate.

In addition, the collaborative working group also contributes to the change of the typical students' passive attitude from the outset of the academic path, smoothing the way for their self-esteem which leads to an active and critical participation on the issues of their training.

\section{REFERENCES}

[1] OECD. "Review of the tertiary education, research and innovation system in Portugal", Feb 2018, pp. 29, in press.

[2] K. A. Livingstone, "Constructive alignment and the curriculum: a call for improved pedagogical practices in higher education", Journal of Business Management \& Social Sciences Research, vol.3, $\mathrm{n}^{\mathrm{o}} 12$, December 2014.

[3] A. M. Soares, M. R. Pinheiro and J. M. Canavarro, "Transição e adaptação ao ensino superior e a demanda pelo sucesso nas instituições portuguesas", Revista Psychologica, Imprensa da Universidade de Coimbra, vol. 58, $\mathrm{n}^{\circ} 2,2015$, pp. 97-116.

[4] P. Neves, "Ensino profissional: expectativas de carreira e projecto de vida", Dissertação de Mestrado em Ciências Sociais e Humanas, Universidade Nova de Lisboa, 2012. http://hdl.handle.net/10362/8343.

[5] A. S. C. Rodrigues, "A matemática no ensino profissional, os programas e as representações dos professores", $\mathrm{PhD}$ Thesis, Universidade da Beira Interior, 2015.

[6] M. Harmin and M. Toth, "Inspiring active learning: a complete handbook for today's teachers", Association for Supervision and Curriculum Development, expanded 2rd ed, 2006.

[7] A. Tashakkori and C. Teddlie, "Combining qualitative and quantitative approaches", Applied Social Research Methods Série, vol.46, Thousand Oaks, CA: Sage Publications, 1998.

[8] D. W. Shaffer and R. C. Serlin, "What good are statistics that don't generalize?", American Educational Research Association, vol. 33, nº 9, 2004, pp. 14-25.

[9] M. E. Diane, R. N. Johnson, S. Milner and M. P. Kathryn, "The Penn State teacher II: learning to teach, teaching to learn." University Park, PA, The Pennsylvania State University, 1997.

[10] J. Biggs and C. Tang, "Teaching for quality learning at university", McGraw -Hill/Open University Press/Society for Research into Higher Education, 4th ed., 2011.

[11] A. Burke, "Group work: how to use groups effectively", The Journal of Effective Teaching, vol 11, nº2, 2011, pp. 87-95.

[12] E. F. Barkley, K. P. Cross and C. H. Major, "Collaborative learning techniques: a handbook for college faculty", San Francisco, Jossey-Bass Publishers, 2014.
[13] R. T. Johnson and D. W. Johnson, "Learning together and alone: cooperative, competitive, and individualistic learning", Boston, MA Allyn \& Bacon, 3rd ed., 1991.

[14] H. Husain, A. S. Salina and D. A. Wahab, "Jigsaw learning technique: addressing problems of implementation", The Social Sciences, vol.8, $\mathrm{n}^{\circ} 6,2013$, pp. 596-599.

[15] L. Betty, H. Angie, G. Neal and W. S. Andrew, "Student learning and perceptions in a flipped linear algebra course", International Journal of Matematical Education in Science and Technology, vol. 45, $\mathrm{n}^{\mathrm{o}} 3,2014$, pp. 317-324. 